\title{
Relative ESR1 gene expression in major depression a biomarker for hormone therapy
}

\author{
${ }^{1}$ Vida farzaneh, khaterh tooba*, mohammad zaefizadeh ${ }^{2}$ \\ department of psychology. Ardabil branch. I.A.U. Ardabil Iran \\ vida57farzaneh@gmail.com \\ department of medicine, Ardabil branch, .I.A.U. Ardabil. Iran \\ k.touba@iauardabil.ac.ir \\ 3_department of genetic. Ardabil branch Ardabil. Iran \\ mzaefi@gmail.com,mzaefi@iauardabil.ac.ir \\ Corresponding author: k.touba@iauardabil.ac.ir
}

\begin{abstract}
:
Depression is a common disease which emerges with a disorder in temper. It results from environmental genetically and physiological factors. One of the effective factors can be the change in hormones and disorder in their intake through cells. In way that one can explain these hypotheses with post-pregnancy depression. The present study aimed to compare estrogen receptorl gene expression in patients with major depression and healthy individuals. The study used causal-comparative method. For this study, 17 patients who suffered major depression referred to the clinic and 30 healthy subjects were randomly selected. After taking blood samples, estrogen receptor 1 gene expression was carried out using Real Time PCR. The results showed that the expression of ESRI gene was significantly reduced in patients with major depression (P value <0.05). This result showed that ESRI gene can be used as a genetically marker for major depression. Also, stimulating estrogen receptor 1 or raising the estrogen level of blood can be applied to reduce depression signs.
\end{abstract}

Keywords: ESR1 gene expression, major depression

\section{Introduction}

Among all psychological disorders, major depression disorder is of the most prevalence in life, reaching 17 percents ${ }^{1}$. Considering that evaluation of major depression is carried out by viable questionnaires and answering them is affected by environmental and situational status of the testees, it seems that using genetic marker would be required. There are a few studies about the role of genes in behaviors and tempers; but, it is evident that some of genes, directly or indirectly, affect on this process and work as a connector between sexual genes and their receptors. Environmental and genetic effects and their interaction as well as multi factorial nature of major depression all clearly demonstrate that none of these elements can be studied separately concerning advent and intensity of depression. Therefore, this very study attempts to consider whether a relation exists inestrogen receptor gene expression between people 
suffering major depression and healthy people, and also, does estrogen receptor gene have any role in depression. Scientists haven't found genes responsible of depression. However, different kinds of genes, called polymorphism, promote the risk of depression ${ }^{2}$. Reliable identification of depression using molecular methods along with influential medical procedures are utilized in lowering effects of environmental factors. Very few and paradoxical studies are available in this context. Psychogenetic studies among people suffering major depression and comparing them with healthy people contribute in introducing a reliable marker in the process of medical diagnosis of this disorder. This, per se, creates a fundamental and functional basis in initial diagnosis of disorder, even in fetus.

Many factors are involved in etiology of depression including age, social factors, personal and mental factors as well as biological factors like physical conditions, hormonal disorders, medicines and heredity disorders ${ }^{3}$. American Psychological Association indicates temperament, environmental, genetic and physiological factors as risky factors in depression. Among genetic factors, change in gene expression, including DRD, DRD2, DRD1, ATPASE, DRD COX, 4, DRD5 3, and serotonin receptor, and also some polymorphisms of genes like ESR1 and ESR2, can be mentioned. Estrogen receptor gene places on chromosome 6q25.1 and consists of 8 exons. Many kinds of polymorphism have been discovered in this gene ${ }^{4}$. With regards to positive role of ESR1 in developing cerebral function, a variety of studies considered relation between ESR1 gene and different behavioral phenotypes. In studies relating to depression and polymorphism of ESR1, a stream of results has been presented. A study with 2468 old women suggested a significant correlation between polymorphisms rs2234693 and rs9340799 and reduction in depression symptoms ${ }^{5}$. Moreover, studies have identified the effect of estrogen on depression ${ }^{6-10}$. Generally, women would face with more fluctuations in their level of estrogen ${ }^{11,12}$. Strong findings are in hand relating to efficiency of estrogen-based medications for pre-menstrual depression in women ${ }^{13,14}$. Also, the relation between some micro-cerebral elements, such as vitamin D, and level of depression has been considered ${ }^{15}$. Evidence indicates that there is a correlation between polymorphisms of ESR1 and postpartum depressive disorders, depression and schizophrenia ${ }^{16}$. Epidemiologic studies confirm finding indicating relation of estrogen with depression and anti-depressive reactions ${ }^{11}$. Menstrual changes are related with both reduction in level of estrogen and risk of early depression ${ }^{17,18}$. Moreover, estrogen works with intracellular activation of estrogen receptors ${ }^{19}$. Reviewing previous studies suggests that, although there are findings about relation between polymorphism of ESR1 and gender, some lack of significant relation. Paradoxical results, in one hand, and lack of studies concerning significant relation in ESR1 gene expression, on the other hand, indicate differences in theories about genetic effects on depression. A variety of studies have been carried out in relation to ESR genes and mutations and their relation with depression. However, no empirical study is available for changes in gene expression. The purpose of this study is to compare ESR1 gene expression between people suffering major depression and healthy people.

\section{Materials and Methods}


The method of study is causal-comparative. Estrogen receptor gene is the independent variable in both groups. The statistical society consisted of all depressed patients in psychological clinic in Shahriar city in 2014. 17 depressed people were selected using random convenient sampling method, ranging 20 to 35 years old. Applying Beck questionnaire and approval of psychologist, the participants`depression was approved. 30 healthy people were chosen with the same age range. After receiving written consent, $3 \mathrm{mls}$ blood were drawn from every patient. After three hours, Roche kit was used to extract RNA. Extracting RNA, primer design was performed by Primer Software version 3. Through blasting in DATA BASE, human genome was confirmed. Primers were synthesized according to relevant sequence (table 1).

Table 1: Sequence of primers in experiment

\begin{tabular}{|c|c|c|}
\hline sequence & direction & item \\
\hline AACAAAGGCATGGAGCATCT & $\mathrm{F}$ & \multirow[t]{2}{*}{ ESR1 } \\
\hline GATGAAGTAGAGCCCGCAGT & $\mathrm{R}$ & \\
\hline AGTAGAGCCCCAGCCACA & $\mathrm{F}$ & \multirow[t]{2}{*}{ GAPDH2 } \\
\hline CGTCCAAATCCATTGATGC & $\mathrm{R}$ & \\
\hline
\end{tabular}

To synthesize CDNA, QLA gene Kit and oligodt primer were applied, in temperature of 42 for 60 minutes. To quantitatively evaluate ESR1 gene, syber green kit was used. Gene expression was carried out using Real Time PCR in GAPDH2 gene. After standardization of data with $E^{-}$ ${ }^{\Delta \Delta c t}$ method, they were compared with t-test.

\section{Findings}

The testees were in the range of 20 to 35 years old (table 2).

Table 2: Age distribution in healthy people and people with major depression

\begin{tabular}{|c|c|c|}
\hline Group & major depression & healthy \\
\hline & percent & percent \\
\hline $20-25$ & 36.56 & 41.11 \\
\hline $26-30$ & 36.56 & 41.11 \\
\hline $31-35$ & 26.88 & 17.78 \\
\hline
\end{tabular}

More than 73 percent of testees are in major depression group, in range of less than 30 years old. In control group, 82 percents are in this group. In fact, testees were in 20 to 30 -year-old category.

Mean of people with major depression was 32.35, with SD of 7.98. In healthy people, this mean was lower, i.e. 5.58.

Table 3: mean of depression scores and results of t-test in both groups 


\begin{tabular}{|c|c|c|c|c|}
\hline depression & major depression & 38.51 & 14.99 & 0.001 \\
& healthy & 13.45 & & \\
\hline
\end{tabular}

Based on Beck questionnaire (1961), mean of depression scores in patients was 38.51, placing in major depression and was approved by psychologist. In contrast, mean of depression for healthy people was 13.45 . This puts people in healthy category. The difference between means was significant ( $\mathrm{p}$ value $=0.001$ ). This test can be applied in proper molecular studies.

ESR1 gene expression was studied with Real Time PCR. Results of CT and TM are shown in figures 1 and 2. Cycloid of growth curve and sharpness of TM curve indicate high efficiency of ESR1 gene.

Figure 1: level of CT in ESR1 and GAPDH3 gene expression

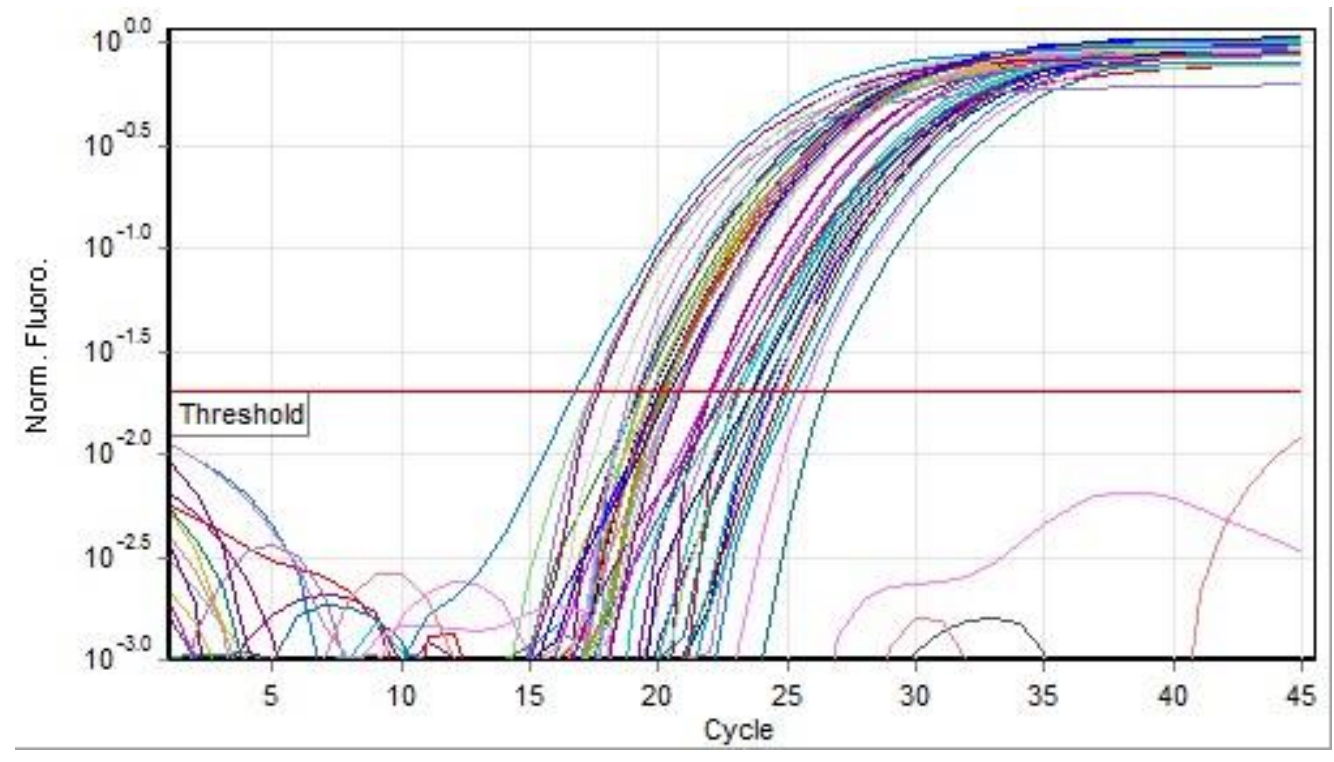

Figure 2: TM curve of ESR1 gene in growth with Real Time PCR

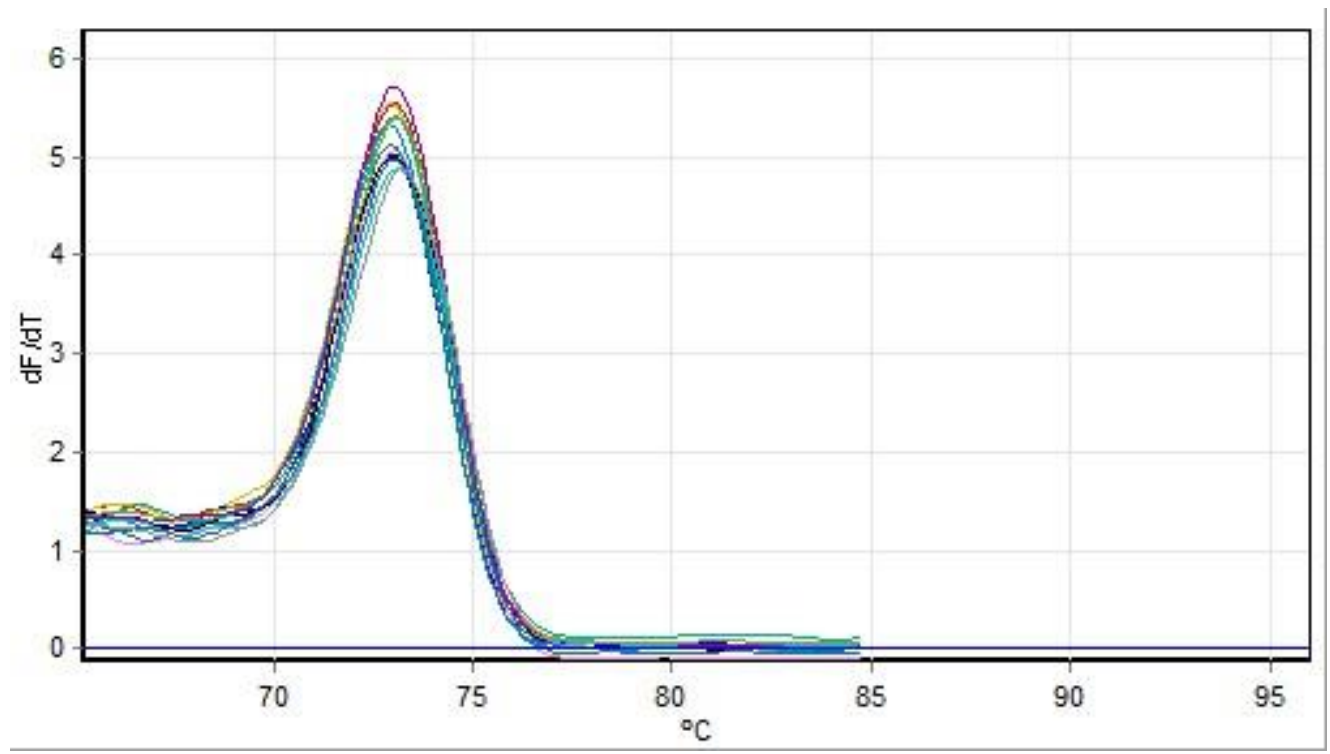


Table 4: results of comparison of both groups in terms of ESR1 gene expression

\begin{tabular}{|c|c|c|c|c|}
\hline item & mean & SE & T & P value \\
\hline healthy & 1 & 0.01 & 16.21 & 0.001 \\
major depression & -21.52 & 2.6 & & \\
\hline
\end{tabular}

Comparison of both groups in terms of ESR1 gene expression was carried out using independent t-test. Mean of ESR1 gene expression in major depression group to healthy people was -21.52 , indicating reduction in gene expression. This reduction was significant in terms of $\mathrm{t}$-test $(\mathrm{P}$ value $=0.001)$.

Considering ESR1 gene expression in major depression group showed that a significant reduction was occurred in this group (figure 3). This finding is consistent with fluctuations in estrogen system and its role in depression ${ }^{20}$.

Figure 3: comparison of ESR1 gene expression in people with major depression and healthy people

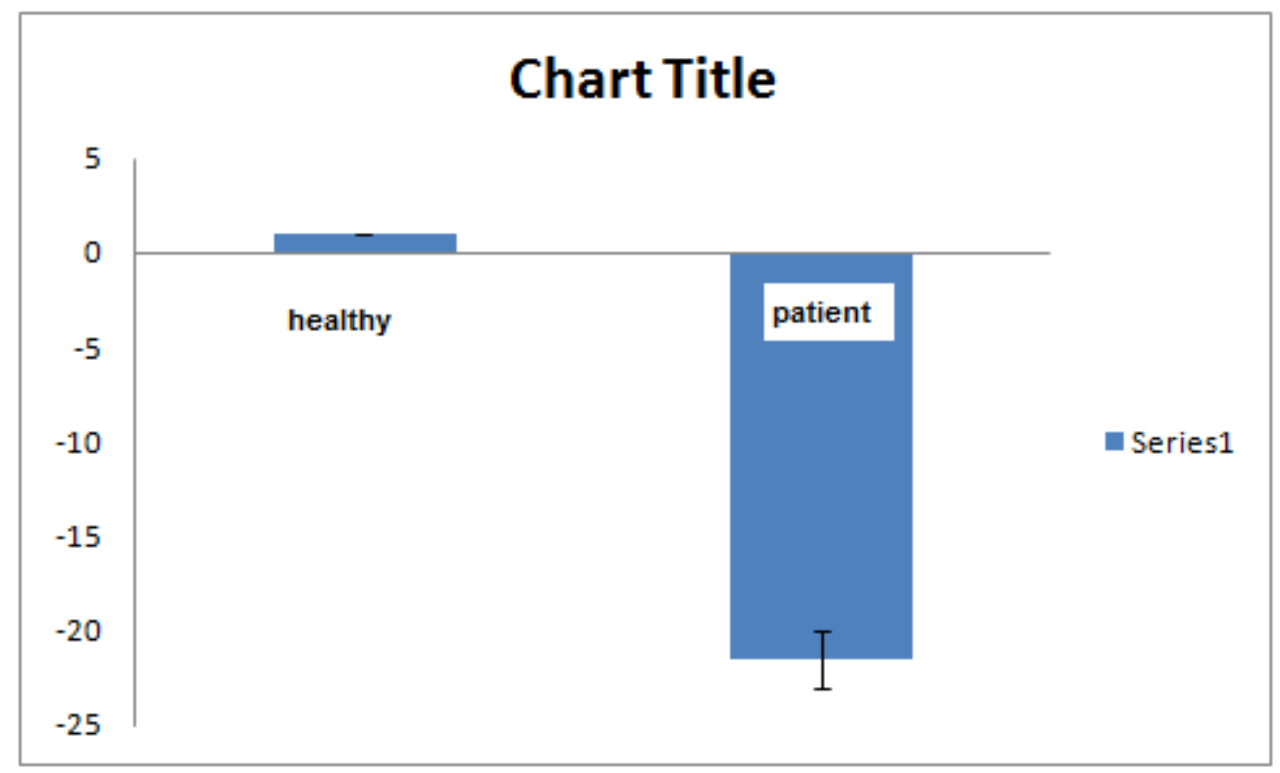

Comparison of ESR1 gene expression in people with major depression and healthy people showed that the level of gene expression is significantly higher in healthy people.

\section{Discussions and Results}

Depression is a common psychological disorder which was among the first prevalent psychological conditions in people around the world in 2020. In Iran, depression is in the third 
rank of medical problems ${ }^{21}$. Prevalence of depression in women is three times more than in $m^{22}$. Major depression is among depression disorders. Diagnosis of five or more of the following symptoms for 2 weeks or more along with reduction in social, working and personal functions can be considered as the signs of Major Depression Disorder (MDD): depressed temper, reduction in interests and pleasures, drastic weight loss, insomnia or much sleeping, lack of proper psychological and motor status, burnout and lack of energy, feeling of worthlessness, lack of focus and continued thinking to death. Risky factors of major depression include 3 groups: temper, environmental and genetic and physiological (DAM-5). Recent studies have emphasized on the role of genetic factors in depression, and report that hereditary factors possess 40 to 50 percent of problems ${ }^{23}$. Studies suggest that major depression in one of the parents would substantially lead in 10 to 13 percent risk of symptoms in offspring ${ }^{1}$. The effect of changes in Dopamine and Notrophin receptors expression has been studied ${ }^{24}$. Researches confirm the vital role of estrogen hormone in depression. In addition, depression is the result of disorder in the level of serotonin, and estrogen mediates performance of neural receptors and estrogenic operations ${ }^{20}$. Epidemiologic studies confirm that estrogen is related with depressed temper and anti-depressive reactions ${ }^{19}$. Treatments with estrogen improve depressed temper of postmenopausal women. Also, evidences show that a correlation exists between polymorphisms of ESR 1 and advent of depression disorders in postpartum, depression and schizophrenia ${ }^{16}$. ESR1 is of the capability of working as a marker in major depression disorder.

Comparing ESR1 gene expression in MDD people manifested that its expression was significantly reduced (table 4). This finding is in line with fluctuations in estrogen system and its role in depression. Studies indicate that depression results from disorder in neurochemistry of brain, including changes in the level of transmitter and abnormal activity of hypothalamicpituitary-adrenal axis ${ }^{25}$. Treatment with promoting cerebral levels of neural transmitters like serotonin and norepinephrine can improve depression symptoms ${ }^{26}$. Estrogen, on the other hand, is able to mediate output of neural transmitters through promoting levels of serotonin and norepinephrine ${ }^{27}$. It seems that polymorphism of ESR1 gene is effective in MDD and bi-polar disorder, in a way that, reduction in its gene expression would culminate in major depression disorder. ESR1 is the receptor of estrogen locating in cell membranes. It controls intake of estrogen through mutual interaction ${ }^{28}$. In MDD, reduction in ESR1 leads in improper interaction, and even in the case of production of estrogen, its intake will be decreased in cells. Reduction in estrogen`s intake surface and activity contributes in reduction in cellular energy surface and increase in occurrence of MDD. Relation of estrogen with other micro molecules, proteins and genes has been confirmed.

Comparison of ESR1 gene expression in people with major depression and healthy people indicated that gene expression is significantly higher in healthy people. Substantial reduction in ESR1 gene expression can be utilized as a marker in genetic studies of depression. This finding can be related to effective neurotransmitters in depression like dopaminergic, notrophin and serotonin, because reduction in ESR1 gene expression will finally contribute in preventing intake of estrogen inside of cells. This is consistent with depression treatment in postmenopausal women ${ }^{25}$. The main question is that whether major depression is the reducing 
factor of ESR1 or lowering gene expression of ESR1 will lead in depression? Therefore, it is required to carry some studies in order to find proper answers. What is evident is that marker of reduction in ESR1 gene expression is a permanent genetic marker which can be applied in evaluating depression.

\section{Conclusion}

Major depression is a psychological disorder originates from environmental and genetic factors. This article indicates that ESR1 gene faces with significant reduction in people with major depression. It seems this phenomenon is related with polymorphisms of ESR1 gene, because polymorphism, especially in promoter, and non-absorption of estrogen into cell due to reduction in ESR1 expression and lack of couple trans-element estrogen to sis-element promoter of ESR1 gene, lead in lower cellular estrogen. This process ends with reduction in neurotransmitters and major depression. Therefore, significant gene expression in ESR1 can be considered a genetic marker for major depression. This is applicable for hormonal treatment of postpartum depression.

\section{Acknowledgment}

We would like to thank Professor Sir John Gurdon, Professor Sir Venki Ramakrishnan, Professor Thomas N. Seyfried, Professor Sir David Baulcombe, for their informational support and the University of Cambridge, Gurdon Institute and Weston A Price Foundation for their Financial and Inspirational Support.

\section{References}

1- Sadock B, Sadock V. Pocket Handbook of Clinical Psychiatry. $5^{\text {th }}$ ed. New York: Lippincott Williams \& Wilkins, a Wolters Kluwer.(2010); 206 - 36.

2- Marijeaan HR, Sanjay J, Mathew; Dennis S, Charney. Neurobiological mechanisms in major depressive disorder. CMAJ.(2009). 180(3): 305-13.

3- Budziszewska B, Szymanska M, Leskiewicz M, Basta-Kaim A, Jaworska -Feil L, Kubera $\mathrm{M}$, et al. The decrease in JNK- and P38- MAP kinase activity is accompanied by the enhancement.(2010); 612:207-15.

4- Herrington DM, Howard TD, Brosnihan KB, McDonnell DP, Li X, Hawkins GA, et al. Common estrogen receptor polymorphism augments effects of hormone replacement therapy on E-selectin but not C-reactive protein. Circulation. (2002); 105: 1879-82.

5- Tiemeier H, Schuit SC, den Heijer T, van Meurs JB, van Tuijl HR, Hofman A, et al. Estrogen receptor alpha gene polymorphisms and anxiety disorder in an elderly population. Mol Psychiatry.(2005); 10: 806-7. 
6- Malacara JM, Perez-Luque EL, Martinez-Garza S and Sanchez-Marin FJ. The relationship of estrogen receptor-alpha polymorphism with symptoms and other characteristics in postmenopausal women. Maturitas.(2004); 49: 163-69.

7-TakeoC, Negishi E, Nakajima A, et al. Association of cytosine-adenine repeat polymorphism of the estrogen receotor-beta gene with menopausal symptoms.Gend Med.(2003);2:96-105.

8- Mill J, Kiss E, Baji I, Kapornai K, Daroczy G, Vetro A, et al. Association study of the estrogen receptor alpha gene (ESR1) and childhood-onset mood disorders. Am J Med Genet.(2008)

9- Geng YG, Su QR, Su LY, et al.Comparison of the polymorphisms of androgen receptor gene and estrogen alpha and beta gene between adolescent femaleswith first-onset major depressive disorder and controls.Int J Neurosci.(2007);117:539-47.

10- Zhou B, Sun X, Zhang M, Deng Y, Hu J. The symptomatology of climacteric syndrome: whether associated with the physical factors or psychological disorder in perimenopausal/postmenopausal patients with anxiety-depression disorder. Arch Gynecol Obstet. .(2012)

11- Ancelin ML, Scali J, Ritchie K. Hormonal therapy and depression: Are we overlooking an important therapeutic alternative?. J PsychosomRed .(2007); 62: 473-85.

12- OsterlundMK.Underlying mechanisms mediating the antidepressant effects of estrogens. BiochimBiophysActa.(2010);1800(10):1136-44.

13- Halbreich U, Borenstein J, Pearlstein TKahn L and S. The prevalence, impairment, impact, and burden of premenstrual dysphoric disorder. Psychoneuroendocrinology.(2007);28(Suppl 3):1-23.

14- Ryan J, Carriere I, Scali J, Ritchie K, Ancelin ML. Lifetime hormonal factors may predict late-life depression in women. IntPsychogeriatr.(2008); 20: 1203-18.

15- Krabel M. et al. The Association between Depression and Vitamin

D.ijp.mums.as.ir.Vol4 p 1365-1372

16- Lukhaus C, sand PG. Estrogen receptor 1 gene(ESR1)variants in Alzheimers disease. Results of a meta-analysis.AgingClinExp Res.( 2007);19:165-8.

17- Cohen LS, Soares CN, Vitonis AF, Otto MW, Harlow BL. Risk for new onset ofdepression during the menopausal transition: the Harvard study of moods and cycles. ArchGen Psychiatry.(2006);63(4):385-90.

18- Freeman EW. Associations of depression with the transition to menopause.Menopause.(2010);17(4):823-7.

19- Soares CN, Almeida OP, Joffe H, Cohen LS. Efficacy of estradiol for the treatment of depressive disorders in perimenopausal women: a double-blind, randomized, placebocontrolled trial. Arch. Gen. Psychiatry.(2001); 58: 529-34.

20- McEwen BS, Alves SE. Estrogen actions in the central nervous system. Endocr Rev.(1999); 20: 279-307.

21-Montazeri A, MosaviJ ,Omidvari,S.Tavoosi M, Hashemi A, RasmiT.UnivercityDepression.Personality Quarterly.6:10-13

22- BaraheniM,Birashk B, Zamani R, SHamloo S, SHahrarai M, Karimi Y, Gahan Y, Mohiaddin M, Hashemian K. CompletTranslation of HilgardPsycology Text.(2014).19 ${ }^{\text {st }}$ ed.Tehran:Roshd;2014:536-39

23-Zamanloo KH, Abolghasemi A, Zaeifizadeh M. Genes expression and stress in depressive patients and healthy. European Journal of Experimental Biology.(2013). 3(1):332-6. 
24-Saeely E, Abolghasemi A, Zaeifizadeh M. Comparative of relative Norotrophin Gene Expression in Major Depression and healthy person. M.A Psycology. Islamic Azad Univercity.1394.

25-Mokrani MC, Duval F, Crocq MA, Bailey P, Macher JP. HPA axis dysfunction indepression: correlation with monoamine system abnormalities.Psychoneuroendocrinology.(1997);22 (Suppl 1): 63-8.

26-Hirschfeld RM. History and evolution of the monoamine hypothesis of depression.JClin Psychiatry.(2000);61 (Suppl 6):4-6.

27-Andrade TG, Nakamuta JS, Avanzi V, Graeff FG.Anxiolytic effect of estradiol in themedian raphe nucleus mediated by 5-HT1A receptors.Behav Brain Res.(2005) ;163(1):1825 .

28-Oslen L .Rasmussen H, Hansen T, et al.Variations in estrogen receptor alpha and risk for cognitive impairment in postmenopausal women.Psychiar Genet.(2006);16:85-8. 